\title{
Control of a Benchmark CSTR Using Feedback Linearization
}

\author{
Malek Hajaya ${ }^{1 *}$, Tamir Shaqarin ${ }^{2}$ \\ ${ }^{1)}$ Civil Engineering Department, Tafila Technical University, Tafila, 66110 Jordan \\ ${ }^{2)}$ Mechanical Engineering Department, Tafila Technical University, Tafila, 66110 Jordan
}

Output regulation control for a CSTR benchmark problem is considered using a feedback linearization technique, where a linear control method is applied to the system for the purpose of maximizing the yield of a desired product at a specific operational temperature. Simulation results showed that the proposed feedback linearization-based controller strategy was successful in maintaining the desired product concentration at its set points, while maintaining the cooling jacket temperate fixed at all times, and the manipulated variables were maintained within their respective operational limits. The proposed feedback linearization-based controller provided very promising results, where it guaranteed a precise operation of the reactor with good performance in terms of a stable transition with no overshoot, and exhibited robustness by rejecting the tested disturbance in the form of a sinusoidal time variation in the reactant feed concentration.

Keywords: Process control, Feedback linearization, Klatt-Engell CSTR, State regulation

\section{Introduction}

Continuously Stirred Tank Reactors (CSTRs) are processing units that are commonly used in various continuous production, reaction-based, operations. Process related conditions and/or economic considerations require the operation of such reactors to be at an optimal point, where a desired product yield is maximized or the production cost is minimized (Edgar et al., 2001). This feat requires maintaining a specific set of operational conditions that dictate the processes inputs and outputs (i.e. input-output constraints) is undertaken by process control. One of the most widely adopted benchmark problem for the aforementioned situation is the CSTR reactor model presented by Klatt and Engell (Klatt and Engell, 1993; Kroll and Schulte, 2014), which include the reaction scheme originally presented by van de Vusse (Van de Vusse, 1964). The Klatt and Engell reactor model includes a realistic process that includes temperature-sensitive, consecutive and parallel liquid phase reactions, under actual physical considerations (Kroll and Schulte, 2014).

In-process control, a CSTR represents an open, non-linear, reaction system model that has balance equations that combine kinetics and hydrodynamics. A variety of approaches are proposed for the control of the aforementioned benchmark problem in the literature: Chen et al (Chen et al., 1995) used nonlinear predictive control to maintain the operation of the CSTR at a desired set point by considering a multi-input and single-input control problems. Klatt and Engell (Klatt and Engell, 1998) have used the principle of gain-scheduling, while Rothfuss et al (Rothfuss et al., 1996) used a flatness-based control approach. Graichen et al (Graichen et al., 2004) and Perez et al (Perez et al., 2002) introduced an inversion-based feedforward control design, while Kvasnica et al (Kvasnica et al., 2010) proposed a method to approximate the nonlinear behavior of the system by several local linear models, thus allowing for a piecewise affine (PWA) model representation that predicted and optimized the reactor behavior. Abdalla and Shaqarin ( Abdalla and Shaqarin et al., 2017) have successfully implemented an alternative LMI (Linear matrix Inequality) approach on a CSTR for temperature and level control using LPV (linear parameter Varying) controller. In this work, state regulation control for the Klatt-Engell CSTR benchmark problem is considered using a feedback linearization technique, where a linear control method is applied to the system for the purpose of controlling the yield of a desired product at a specific operational temperature. Controlled and uncontrolled CSTR performance are compared at nominal conditions, and with an added disturbance in the reactant feed concentration. This alternative approach for state regulation control maintain the effect of the nonlinear part on the system's performance by using exact state transformations and feedback, rather than by linear approximations of the dynamics.

Received on July 2, 2019, accepted October 27, 2019. Correspondence concerning this article should be addressed to Malek G. Hajaya (E-mail address: mhajaya@ttu.edu.jo).ORCID ID for Malek G. Hajaya: https://orcid.org/0000-0003-0110-6731 


\section{Materials and Methods}

\subsection{The CSTR benchmark model}

The benchmark model represents a constant volume CSTR with a constant volume. The reactions (Chen et al., 1995; Rothfuss et al., 1996) are taking place in the liquid phase, and represent the process of substance $B$ production. This chain of irreversible reactions represents the production of Cyclopentenol (B) from Cyclopentadiene (A) via an acid-catalyzed electrophilic addition of water in dilute solution. Additionally, Dicyclopentadiene (D) is generated as a side product and Cyclopentanediol (C) as a consecutive product. Figure 1 illustrates the CSTR reactor in the benchmark model, along with the variables used in the benchmark model.

$A \stackrel{k_{1}}{\rightarrow} B \stackrel{k_{1}}{\rightarrow} C$

$2 A \stackrel{k_{2}}{\rightarrow} D$

where $k_{1}(1 / \mathrm{hr})$ and $k_{2}\left(\mathrm{~mol} / \mathrm{m}^{3}\right)$ are reaction rate constants for reactions 1 and 2 . Reactant $A$ is used to produce $B$, while undesired reactions take place producing two by-products $(C$ and $D$ ) (Rothfuss $e t$ al., 1996). Both steps of reaction 1 follow the same mechanism, thus the same reaction rate constant $\left(k_{l}\right)$ is used for both steps (Klatt and Engell, 1993). As shown in the figure, the continuously mixed reactor, with an active volume of $V$, is fed by reactant $A$ at a feed flow rate of $Q_{\text {in }}(\mathrm{L} / \mathrm{hr})$, a concentration of $c_{\text {Ain }}\left(\mathrm{mol} / \mathrm{m}^{3}\right)$, and a temperature of $T_{\text {in }}$

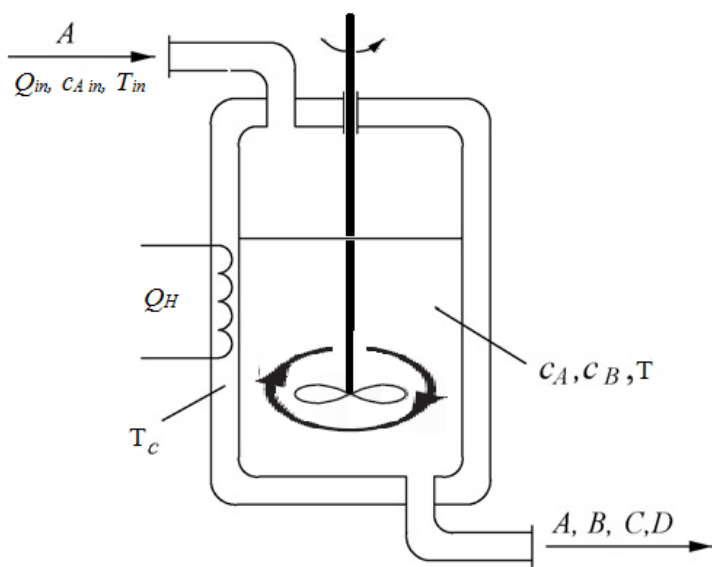

Fig. 1 Representation of the CSTR problem deferent variables.

$\left({ }^{\circ} \mathrm{C}\right)$. The feed temperature is subject to variation. None of the products are present in the feed. The reactor effluent is at temperature $T\left({ }^{\circ} \mathrm{C}\right)$, with $A$ and $B$ concentrations of $c_{A}$ and $c_{B}\left(\mathrm{~mol} / \mathrm{m}^{3}\right)$, respectively. Heat is removed by a rate of $Q_{H}(\mathrm{~kJ} / \mathrm{hr})$ to maintain the exothermic reactions through the usage of a cooling jacket, which has a temperature of $T_{C}\left({ }^{\circ} \mathrm{C}\right)$, and an external heat exchanger.

Reactions rates for $A$ and $B$ are:

$r_{A}=-k_{1} c_{A}-k_{2} c_{A}^{2}$

$r_{B}=k_{1}\left(c_{A}-c_{B}\right)$

The dynamic behavior of the reactor can be represented by the material for $A$ and $B$ :

$$
\begin{aligned}
& d C_{A} / d t=\left(\frac{Q_{\text {in }}}{V}\right)\left(c_{A i n}-c_{A}\right)-k_{1} c_{A}-k_{2} c_{A}^{2} \\
& d C_{B} / d t=-\left(\frac{Q_{\text {in }}}{V}\right) c_{B}+k_{1}\left(c_{A}-c_{B}\right)
\end{aligned}
$$

In addition to the heat balance between the reactor and the cooling jacket:

$$
\begin{aligned}
& d T / d t=\left(\frac{Q_{\text {in }}}{V}\right)\left(T_{i n}-T\right)-\left(\frac{1}{\rho C p}\right)\left(k_{1} c_{A} \Delta H_{R_{A B}}+k_{1} c_{B} \Delta H_{R_{B C}}+k_{2} c_{A}^{2} \Delta H_{R_{A D}}\right)+\left(T_{C}-T\right)\left(\frac{A_{R} K_{W}}{\rho C p V}\right) \\
& d T_{C} / d t=\frac{Q_{H}}{m_{K} C_{P J}}+\frac{A_{R} K_{W}}{m_{K} C_{P J}}\left(T-T_{C}\right)
\end{aligned}
$$

where $C_{P}$ is the heat capacity of the liquid phase of the reactor, $\rho$ is the density of the liquid phase, $\Delta H_{R A B}$ is enthalpy of the $A \rightarrow B$ reaction, $\Delta H_{R B C}$ is enthalpy of the $B \rightarrow C$ reaction, $\Delta H_{R A D}$ is enthalpy of the $A \rightarrow D$ reaction, $A_{R}$ is the surface area of the cooling jacket, $K_{W}$ is the heat transfer coefficient for the cooling jacket, $m_{K}$ is the coolant mass, and $C_{P J}$ is the heat capacity of the coolant. The reaction rates in Equations 3 and 4 are affected by temperature through the Arrhenius law: 
$k_{i}=k_{i}^{0} \exp \left(\frac{E_{i}}{T+273.5}\right)$

where $i$ denotes reaction rate constants 1 and $2, k_{i}^{0}$ is the collision factor for rate constant $i$, and $E_{i}$ is the activation energy for each of the aforementioned reaction constants (Chen et al., 1995). Concentrations of substances C and D (the by-products) are not considered in the context of the model, and they do not influence the dynamics of the process (Rothfuss et al., 1996). Table 1 illustrates the values for the different physical and chemical parameters in the benchmark model.

As it is shown in Table 1, values of the collision factors and Enthalpy's do indeed have some uncertainty. This work used values of the best estimate in the simulations.

\subsection{The control problem}

The control problem of the specific benchmark model CSTR in hand involves a constrained control problem of a Multiinput Multi-output (MIMO) coupled nonlinear system. Feedback linearization technique is a good candidate for such problem; since it is capable of canceling the nonlinearities (fully or partially) and/or to decouple the model equations. A state feedback controller can be designed based on the feedback linearized system.

\subsection{Feedback linearization}

Feedback linearization is a technique used for nonlinear systems control design. Basically, the nonlinear dynamics of the sys tem to be controlled is algebraically transformed, fully, or partially into a linear one. This enables the usage of linear control techniques in the system's controller (Slotine and Li, 1991). The value of this approach, compared to conventional linearization, stems from the fact that feedback linearization is achieved by exact state transformations and feedback, rather than by linear approximations of the dynamics. Thus, maintaining the effect of the nonlinear part on the system's performance. The mechanistic approach used in feedback linearization, i.e., canceling the nonlinearities and imposing a desired linear dynamics, can be simply applied to a class of nonlinear systems described by the so-called companion form. A system is said to be in companion form if its dynamics is represented by:

$x^{(n)}=f(\mathrm{x})+b(\mathrm{x}) u$

where $u$ is the scalar control input, $x$ is states, $x=\left[x, \dot{x}, \ldots, x^{(n-1)}\right]^{T}$ is the state vector, and $f(\mathrm{x})$ and $b(\mathrm{x})$ are nonlinear functions of the states. This form of a dynamic system model is unique in the fact that it is easily transformed into a linearized system via direct feedback linearization.

The companion from Equation 10 can be transformed to a state-space representation as follows.

$\left[\begin{array}{c}\dot{x_{1}} \\ \dot{x_{2}} \\ \vdots \\ \dot{x_{n}}\end{array}\right]=\left[\begin{array}{c}x_{2} \\ x_{3} \\ \vdots \\ f(x)+b(x) u\end{array}\right]$

The nonlinear state-space is easily transformed to linear one by selecting an appropriate control law in the form of:

$u=\frac{1}{b}[v-f]$

The closed-loop system now is transformed to an equivalent linear state-space equation as follows: 
$\dot{x}^{n}=v$

where $v$ is the linear control law that can be designed via, state-feedback control, optimal control, pole-placement, ... etc. The result is a linear input-output map between the new input and the output. Figure 2 illustrates the input state linearization general form.

The resulting system structure is unique and system-specific, and most of the process systems cannot be represented as such, for instance, the CSTR. Albeit, feedback linearization can be used to fully (Shaqarin and Abdalla, 2009) or partially (Shaqarin et al., 2014) cancel the nonlinearity for CSTR model, and remove the coupling between the state variables, especially, the controlled variables.

In the CSTR problem case, the system state is $x^{T}=\left[c_{A}, c_{B}, T, T_{c}\right]$. Controlled state variables are the effluent substance $B$ concentration $\left(c_{B}\right)$ and the jacket temperature (Tc) (Rothfuss et al., 1996). The cooling jacket temperature is controlled as a means to control the reactor temperature. The manipulated variables are the reactor volume normalized flow rate $Q_{\text {in }} / V(1 / \mathrm{hr})$, and the heat removal rate by the jacket of $Q_{H}(\mathrm{~kJ} / \mathrm{hr})$. From an operational point, $Q_{\text {in }} / V$ is manipulated by changing the flow rate into and from the reactor, while $Q_{H}$ can be manipulated through changes in the coolant flow rate and/or using a multiple heat exchangers setup, to name some. However, these changes can be strictly performed within specific constraints dictated by the process itself. The constraints for the Klatt-Engell CSTR benchmark model manipulated parameters are shown in the next section.

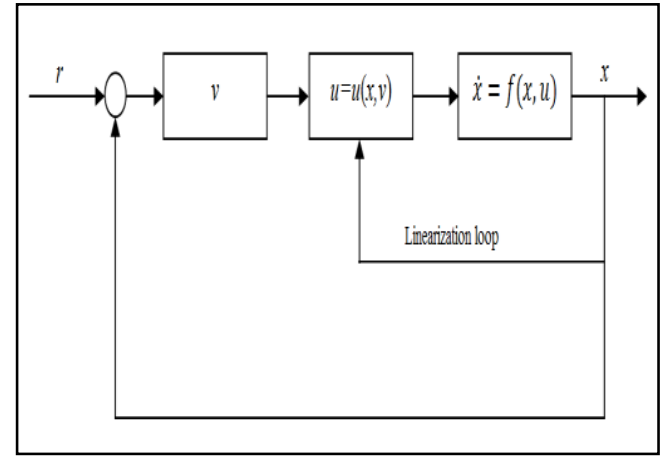

Fig. 2 General form for the input state linearization

\subsection{CSTR operation}

The state regulation problem requires operating the reactor at set points for substance $B$ effluent concentration $\left(c_{B}\right)$, while maintaining the temperature of the cooling jacket $\left(T_{C}\right)$ at a desired value. Table 2 shows the constraints on the state variables (for safe operation) and manipulated variables (Kvasnica et al., 2010; Kroll and Schulte, 2014). In this work, the setpoints for $c_{B}$ is $1.09 \times 10^{3}\left(\mathrm{~mol} / \mathrm{m}^{3}\right)$, which is considered as the point where the maximum yield of $B$ is obtained (Chen et al., 1995). Values for the remaining model variables required to achieve this point (max yield) are shown in Table 3. The cooling jacket temperature is also regulated at 109 $\left({ }^{0} \mathrm{C}\right)$, which is lower than the temperature shown in Table 2. Finally, the CSTR model performance was simulated using MATLAB (The MathWorks Inc., Natick, MA).

\section{Results and Discussion 2.1 Open-loop operation:}

In order to validate the performance of the CSTR model, a simulation was performed for the maximum $B$ yield point mentioned in Table 2. Figure 3 illustrates four plots that represent the simulation result for an open, uncontrolled CSTR. Initial values for the model state variables in the reactor were assumed to be zero $\left(c_{A}, c_{B}, T\right.$, and $\left.T_{C}=0\right)$. After $2 \mathrm{hrs}$ of simulated operation, effluent steady-state concentrations of $A$ and $B$ were $2.113 \times 10^{3}$ and $1.09 \times 10^{3} \mathrm{~mol} / \mathrm{m}^{3}$, respectively, corresponding to a yield of 0.516 for $B$. Reactor and jacket steady-state temperatures were 114.25 and $112.93{ }^{\circ} \mathrm{C}$, respectively. These results were identical to the values reported by Chen et al., (1995) and Rothfuss et al., (1996).
Table 2 Constraints on the state variables and manipulated variables (Kvasnica et al., 2010; Kroll and Schulte, 2014)

\begin{tabular}{ll}
\hline Model variable & Constraints \\
\hline$Q_{\text {in }} / V$ & 5 to 35 \\
$Q_{H}$ & -8500 to 0 \\
& $2.6 \times 10^{3}$ to $3.7 \times$ \\
$c_{A}$ & $10^{3}\left(\mathrm{~mol} / \mathrm{m}^{3}\right)$ \\
& $0.6 \times 10^{3}$ to $1.1 \times$ \\
$c_{B}$ & $10^{3}\left(\mathrm{~mol} / \mathrm{m}^{3}\right)$ \\
$T$ & \\
$T_{C}$ & 80 to $150\left({ }^{0} \mathrm{C}\right)$ \\
\hline
\end{tabular}

Table 3 Operational parameters at maximum, optimal, yield for $B$ (Chen et al., 1995).

\begin{tabular}{ll}
\hline \multicolumn{1}{c}{ Model inputs } & \multicolumn{1}{c}{ Optimal value } \\
\hline$c_{\text {Ain }}$ & $5.1 \times 10^{3}\left(\mathrm{~mol} / \mathrm{m}^{3}\right)$ \\
$T_{\text {in }}$ & $104.9^{0} \mathrm{C}$ \\
$Q_{i n} / V$ & $14.19(1 / \mathrm{hr})$ \\
$Q_{H}$ & $-1113.5(\mathrm{~kJ} / \mathrm{hr})$ \\
$c_{A}$ & $2.14 \times 10^{3}\left(\mathrm{~mol} / \mathrm{m}^{3}\right)$ \\
$c_{B}$ & $1.09 \times 10^{3}\left(\mathrm{~mol} / \mathrm{m}^{3}\right)$ \\
$T$ & $114 .{ }^{\circ} \mathrm{C}$ \\
$T_{C}$ & $112.9^{0} \mathrm{C}$ \\
\hline
\end{tabular}

In order to gain a better understating regarding the performance of the benchmark CSTR problem, multiple simulations were performed using values of the model's manipulated variables within the range depicted in Table 1. Figure 4 shows four plots representing the resulted contour plot for the outcome of the simulation. The figure depicts how each of the state variables varies within the permissible range of the manipulated variables. 


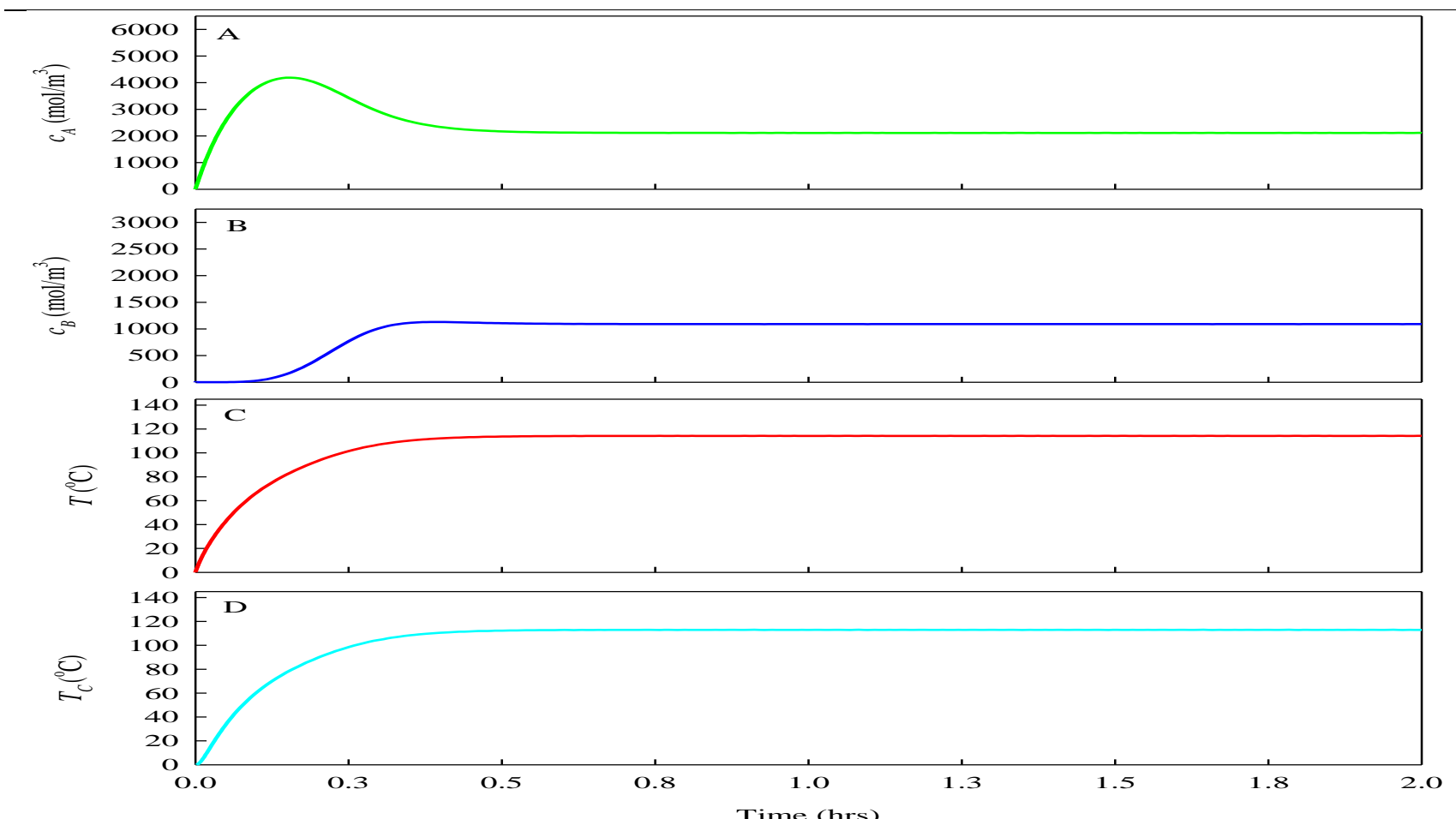

Fig. 3 Simulation results for the CSTR benchmark model at $c_{\text {Ain }}=5.1 \times 10^{3}\left(\mathrm{~mol} / \mathrm{m}^{3}\right), T_{i n}=104.9^{\circ} \mathrm{C}, Q_{i n} / V=14.19(1 / \mathrm{hr})$, and $Q_{H}=-1113.5(\mathrm{~kJ} / \mathrm{hr})$, where A: reactant A effluent concentration, B: Substance B effluent concentration, C: effluent stream temperature, and D: cooling jacket temperature.
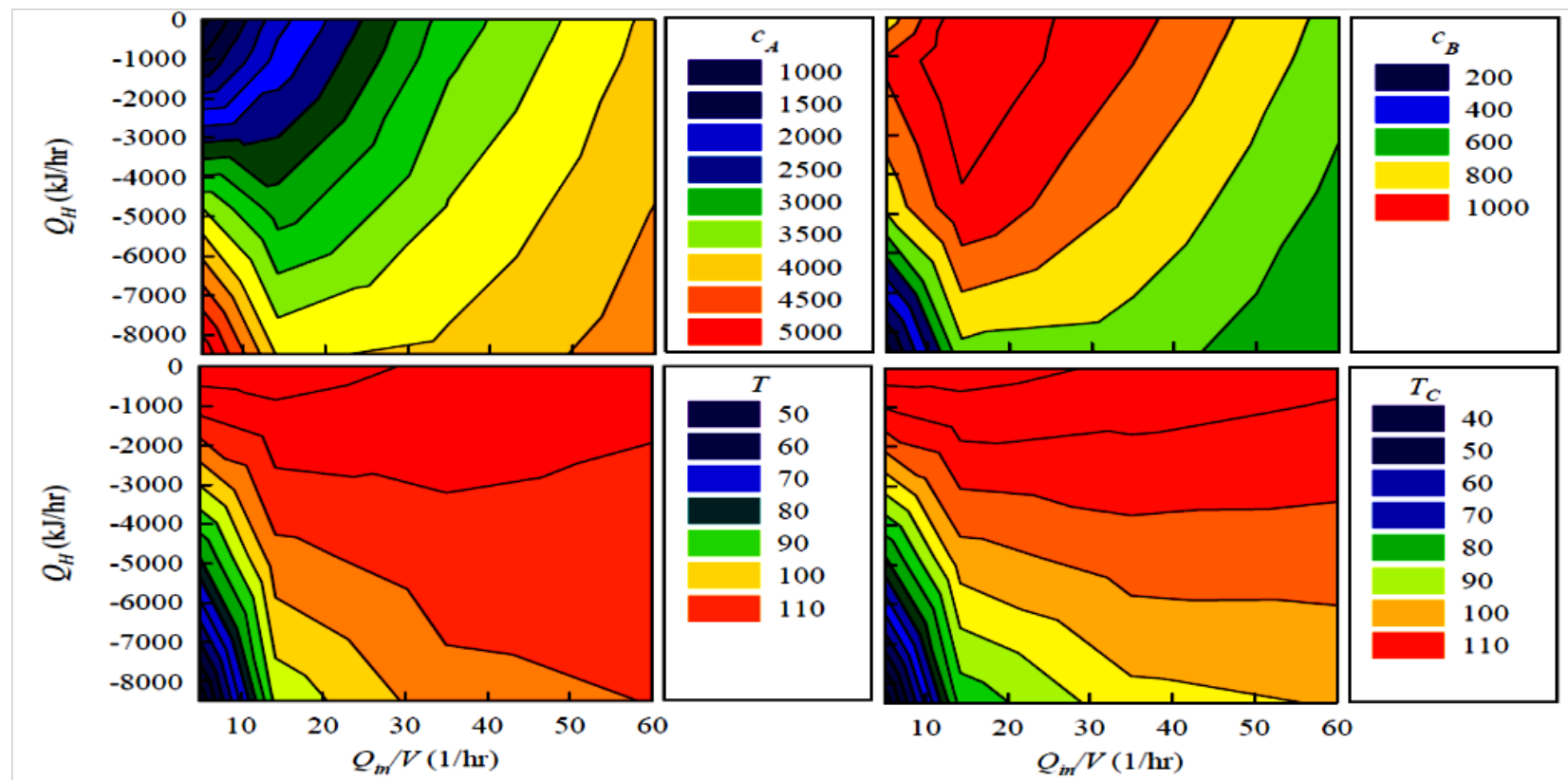

Fig. 4 Contour plot representing the simulated operation of the CSTR benchmark model at $c_{A i n}=5.1 \times 10^{3}\left(\mathrm{~mol} / \mathrm{m}^{3}\right)$ and $T_{\text {in }}=104.9^{\circ} \mathrm{C}$ with the manipulated variables $5 \leq Q_{i n} / V \leq 35(1 / \mathrm{hr})$, and $-8500 \leq Q_{H} \leq 0(\mathrm{~kJ} / \mathrm{hr})$.

As seen in the figure, the maximum concentration of B results from operating with a $Q_{i n} / V$ between about 9 and $25 \mathrm{hr}^{-1}$ and a $Q_{H}$ between about -4200 and $0(\mathrm{~kJ} / \mathrm{hr})$, while maintaining the constraints on the manipulated variables shown in Table 1 . This range corresponded to a reactor temperature and a cooling jacket temperature between about 90 and $117^{\circ} \mathrm{C}$, which for the cooling jacket temperatures encompasses the desired set point for it at a temperature of $109^{\circ} \mathrm{C}$.

\subsection{Output regulation Control}

Typical simulations of the closed-loop nonlinear CSTR system response with feedback-linearization and state-feedback controller are discussed herein. The set-up understudy is to operate the reactor for the purpose of maximizing the yield of the 
desired product B at a specific cooling temperature. Plots in Figure 5 (solid lines) shows the controlled response of the CSTR model with feedback linearization for the operation at a set-point for $c_{B}$ at $0.6 \times 10^{3}$ and $1.09 \times 10^{3}\left(\mathrm{~mol} / \mathrm{m}^{3}\right.$ ), and a set-point for $T_{C}$ at $109^{\circ} \mathrm{C}$, at inputs of $c_{\text {Ain }}=5.1 \times 10^{3}\left(\mathrm{~mol} / \mathrm{m}^{3}\right)$ and $T_{\text {in }}=104.9^{\circ} \mathrm{C}$.
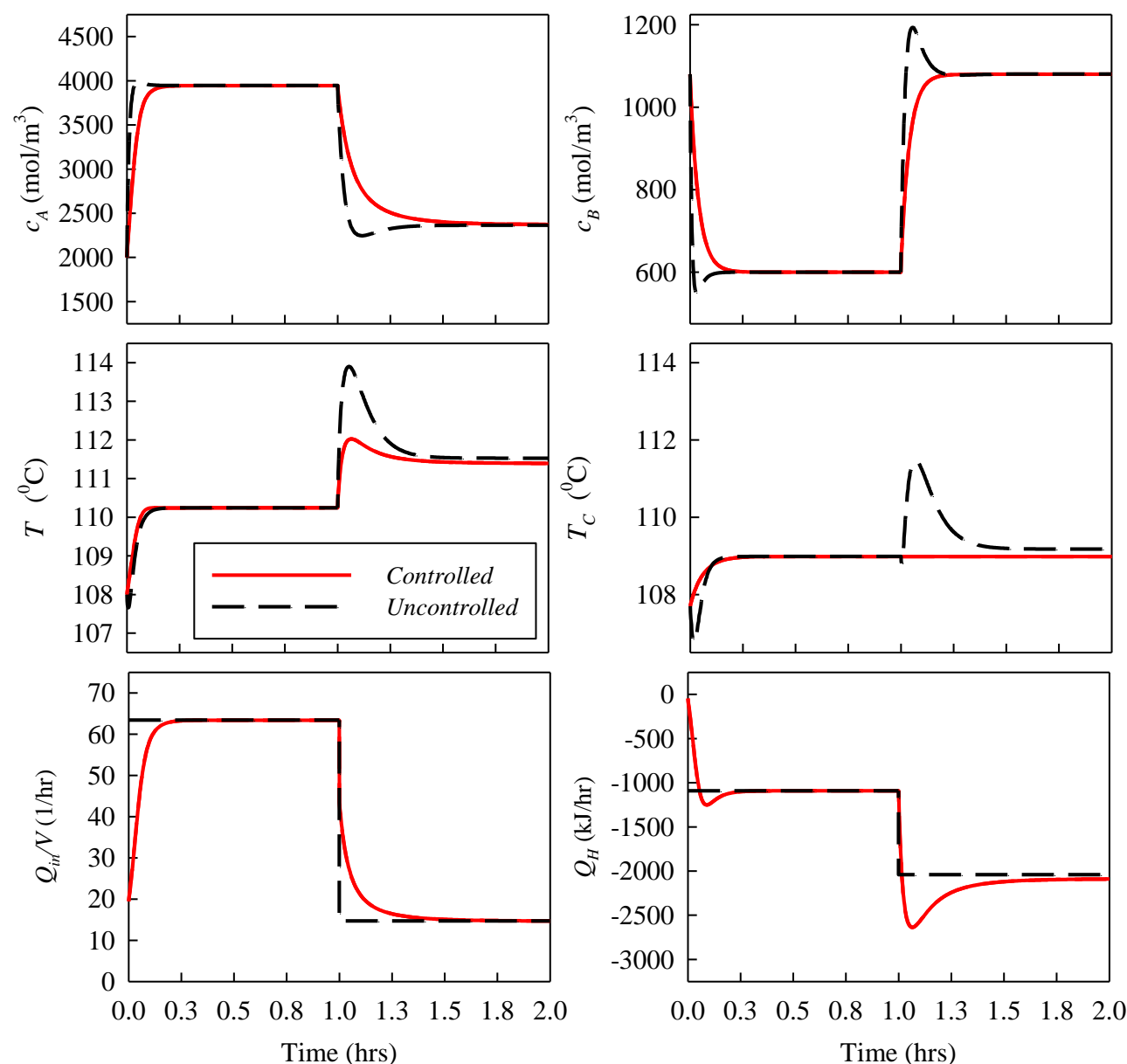

Fig. 5 Solid lines show the simulated controlled operation of the CSTR model with feedback linearization, with the set set-point for $c_{B}$ at $0.6 \times 10^{3}$ and $1.09 \times 10^{3}\left(\mathrm{~mol} / \mathrm{m}^{3}\right)$, and $T_{C}$ maintained at $109^{\circ} \mathrm{C}$, while dashed lines shows the simulated uncontrolled operation of the CSTR at values of $Q_{i n} / V$ and $Q_{H}$ manually changed between 63.4 and $14.6(1 / \mathrm{hr})$ and -1090 and $-2090 \mathrm{~kJ} / \mathrm{hr}$, respectively; at $c_{A i n}=5.1 \times 10^{3}\left(\mathrm{~mol} / \mathrm{m}^{3}\right)$ and $T_{\text {in }}=104.9^{\circ} \mathrm{C}$.

For this nominal scenario, as seen in the figure, the controller was able to regulate the operation of the CSTR, with a settling time of $\approx 0.2(\mathrm{hr})$, to produce $c_{B}$ at the desired maximum yield point. This was achieved by maintaining the desired $T_{c}$ at the given setpoint of $109\left({ }^{0} \mathrm{C}\right)$. The control effort remained within the constraints sanctioned on the system, changing $Q_{i n} / V$ between 63.4 and $14.6(1 / \mathrm{hr})$ and $Q_{H}$ between -1090 and $-2090 \mathrm{~kJ} / \mathrm{hr}$. The same can be said for the remaining state variables, as they remained within the safe operation range (Table 1). The regulation of $c_{B}$ at its maximum yield point was possible with a $T c$ value that is lower than the required temperature for optimal operation (Table 2). This was possible by increasing the heat removal rate at the jacket $\left(Q_{H}\right)$, which increased from $-1113.2 \mathrm{~kJ} / \mathrm{hr}$, to $-2090.8 \mathrm{~kJ} / \mathrm{hr}$. This change slightly reduced the reactor temperature to $111.3^{0} \mathrm{C}$. On the other hand, values of $Q_{i n} / V$ settled back to a value that is almost identical to the optimal point (Table 2). The effectiveness of the proposed control technique can also be shown in Figure 5 (dashed lines), where the simulated uncontrolled operation of the CSTR is depicted. This simulation was performed with the same input of $c_{\text {Ain }}=5.1 \times 10^{3} \mathrm{~mol} / \mathrm{m}^{3}$, and $T_{\text {in }}=104.9^{\circ} \mathrm{C}$. Values of $Q_{i n} / V$ and $Q_{H}$ were manually changed to mimic the range resulting from the controlled operation to be between 63.4 and 14.6 $(1 / \mathrm{hr})$ and -1090 and $-2090 \mathrm{~kJ} / \mathrm{hr}$, respectively. Compared to the controlled operation, the response of $c_{B}$ and $T_{c}$ reached and maintained their desired set points values. However, the controller allowed for a better performance in terms of overshoot and settling time for both outputs.

To test the robustness of the designed controller in disturbance rejection, the regulation control problem was simulated with sinusoidal disturbance as time variation in the inlet concentration substance $A$ concentration $\left(c_{\text {Ain }}\right)$ in the feed by $\pm 100 \mathrm{~mol} / \mathrm{m}^{3}$. Perturbations in $c_{A \text { in }}$ where achieved by changing its value to be: $c_{A \text { in }}=5100+100 \times \sin (8 \times t)\left(\mathrm{mol} / \mathrm{m}^{3}\right)$. Plots in Figure 6 shows the 
simulated controlled response (solid lines) and uncontrolled response (dashed lines) for the CSTR benchmark model with feedback linearization in the presence of the external disturbance $\left(c_{\text {Ain }}\right)$.
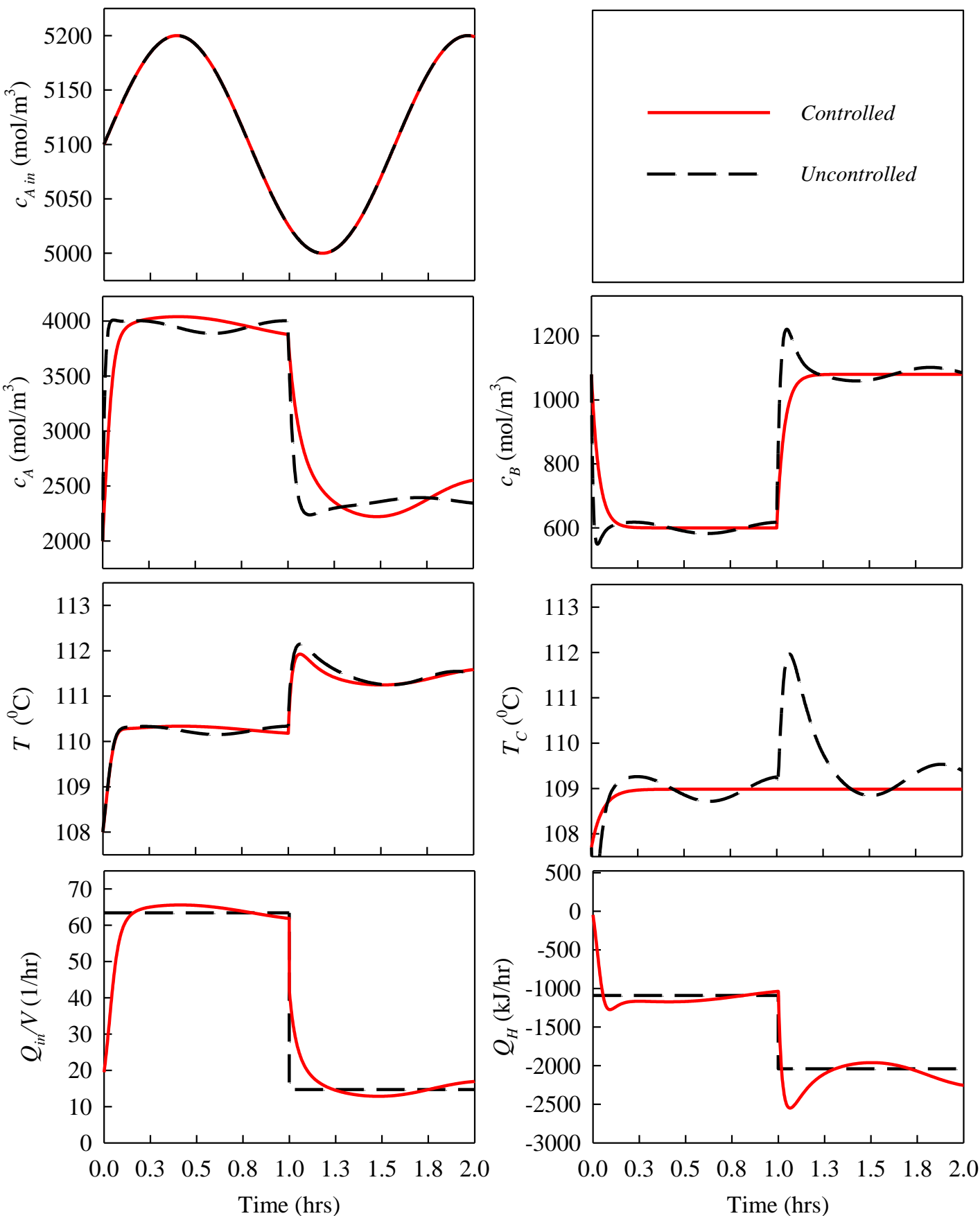

Fig. 6 Solid lines show the simulated controlled operation of the CSTR model with feedback linearization, with the set set-point for $c_{B}$ at $0.6 x 10^{3}$ and $1.09 \times 10^{3}\left(\mathrm{~mol} / \mathrm{m}^{3}\right)$, and $T_{C}$ maintained at $109^{\circ} \mathrm{C}$, while dashed lines shows the simulated uncontrolled operation of the CSTR at values of $Q_{i n} / V$ and $Q_{H}$ manually changed between 63.4 and $14.6(1 / \mathrm{hr})$ and -1090 and $-2090 \mathrm{~kJ} / \mathrm{hr}$, respectively; at $c_{\text {Ain }}=5100+100 \sin (8 \times t)\left(\mathrm{mol} / \mathrm{m}^{3}\right)$ and $T_{i n}=104.9^{0} \mathrm{C}$.

Despite the external disturbance in the inlet reactant concentration in the CSTR feed, the controller was successful in regulating the outputs to the set-points. This observation leads to the conclusion that the controller is robust in disturbance rejection if it is found in the form of time variation of the inlet concentration. Compared to the controlled CSTR behavior, subjecting the uncontrolled CSTR to the same disturbance (dashed lines), resulted in a great degree of disturbance in the behavior of all the model outputs. This clearly shown in Figure 6, which shows how the outputs did not stabilize but rather contaminated with the same frequency of the external disturbance in $c_{\text {Ain }}$. Predictably, the current controller improved the performance significantly and was more robust against external disturbance compared to open-loop control. 


\section{Conclusions}

This study aimed to introduce an alternative approach for controlling an of a complex, highly nonlinear, benchmark chemical reactor, that included a CSTR operating with temperature-sensitive, sequential and parallel reactions. Simulation results show that the proposed feedback linearization-based controller strategy was successful in regulating the desired product concentration to its set points while maintaining the cooling jacket temperate fixed at all times. The proposed feedback linearization-based controller provided very promising results. Not only does the controller guarantee a precise operation of the reactor, it also provided, compared to uncontrolled operation, improved performance in terms of settling time and overshoot. Disturbances in the feed reactant concentration did not affect the performance of the controller. The manipulated variables were maintained within the operational limit for each one of them, and the controller was robust against the tested external disturbance.

\section{Nomenclature \\ Acronyms}

CSTR Continuous stirred-tank reactor

Symbols

A: $\quad=$ Reacting substance

$B: \quad=$ Intermediate, desired product $\quad[-]$

$C: \quad=$ Final product $1 \quad[-]$

D: $\quad=$ Final product 2

$k_{1}$ : $\quad=$ Reaction 1 rate constant $\quad[1 / \mathrm{hr}]$

$k_{2}$ : $\quad=$ Reaction 2 rate constant $\quad\left[\mathrm{m}^{3} / \mathrm{hr} . \mathrm{mol}\right]$

$V: \quad=$ Reactor volume $\quad\left[\mathrm{m}^{3}\right]$

$Q_{\text {in }}: \quad=$ Feed volumetric flow rate into the reactor $\quad\left[\mathrm{m}^{3} / \mathrm{hr}\right]$

$Q_{H}: \quad=$ Jacket heat removal rate $\quad[\mathrm{kJ} / \mathrm{hr}]$

$c_{\text {Ain }}$ : $\quad=$ Substance A concentration in the reactor feed $\quad\left[\mathrm{mol} / \mathrm{m}^{3}\right]$

$c_{A}: \quad=$ Substance A concentration in the reactor and effluent $\quad\left[\mathrm{mol} / \mathrm{m}^{3}\right]$

$c_{B}: \quad=$ Substance $B$ concentration in the reactor and effluent $\left.\quad\left[\mathrm{mol} / \mathrm{m}^{3}\right] 1\right]$

$\begin{array}{lll}T_{\text {in }}: \quad=\text { Reactor feed temperature } & {\left[{ }^{\circ} \mathrm{C}\right]}\end{array}$

T: $\quad=$ Reactor and effluent temperature $\quad\left[{ }^{\circ} \mathrm{C}\right]$

Tc: $\quad=$ Cooling jacket temperature $\quad\left[{ }^{\circ} \mathrm{C}\right]$

$r_{A}: \quad=$ Overall reaction rate for $\mathrm{A} \quad\left[\mathrm{mol} / \mathrm{hr} . \mathrm{m}^{3}\right]$

$r_{B}: \quad=$ Overall reaction rate for $\mathrm{B} \quad\left[\mathrm{mol} / \mathrm{hr} \cdot \mathrm{m}^{3}\right]$

$\triangle H_{R A B}: \quad=$ Enthalpy for the $A \rightarrow B$ reaction $\quad[\mathrm{kJ} / \mathrm{mol} \mathrm{A}]$

$\triangle H_{R A C}:=$ Enthalpy for the $A \rightarrow C$ reaction $\quad[\mathrm{kJ} / \mathrm{mol} \mathrm{A}]$

$\triangle H_{R B C}:=$ Enthalpy for the $B \rightarrow C$ reaction $\quad[\mathrm{kJ} / \mathrm{mol} \mathrm{B}]$

$C_{P}: \quad=$ Heat capacity of the liquid phase of the reactor $\quad[\mathrm{kJ} / \mathrm{kg} . \mathrm{K}]$

$C_{P J}: \quad=$ Heat capacity of the liquid coolant $\quad[\mathrm{kJ} / \mathrm{kg} \cdot \mathrm{K}]$

$A_{R}: \quad=$ Surface area of the cooling jacket $\quad\left[\mathrm{m}^{2}\right]$

$K_{W}: \quad=$ The heat transfer coefficient of the cooling jacket $\quad\left[\mathrm{kJ} / \mathrm{hr} \cdot \mathrm{K} \cdot \mathrm{m}^{2}\right]$

$m_{K}: \quad=$ Coolant mass $\quad[\mathrm{kg}]$

$k_{1}^{0}: \quad=$ collision factor for rate constant $1 \quad[1 / \mathrm{hr}]$

$k_{2}^{0}$ : $\quad=$ collision factor for rate constant $2 \quad\left[\mathrm{~m}^{3} / \mathrm{hr} . \mathrm{mol}\right]$

$E_{i}$ : $\quad=$ Reaction $I$ activation energy $\quad[\mathrm{K}]$

$x: \quad=$ State variables vector $\quad[-]$

$f$ and $b: \quad=$ Functions $\quad[-]$

\section{Greek letters}

$\rho: \quad=$ Density of the reactor liquid phase $\quad\left[\mathrm{kg} / \mathrm{m}^{3}\right]$

\section{References}

Abdalla, M. and Shaqarin, T. "Industrial Process Control Using LPV”, Modern Applied Science, 11 (9), 39-50.(2017).

Chen, H., Kremling, A., and Allgöwer, F. (1995). Nonlinear predictive control of a benchmark cstr. pp. 3247-3252 Proceedings of 3rd European control conference.

Edgar, T.F., Himmelblau, D.M. and Lasdon, L.S.; "Optimization of chemical processes", McGraw-Hill, (2001).

Favache, A. and Dochain, D. "Thermodynamics and chemical systems stability: The cstr case study revisited", Journal of Process Control, 19, 371379.(2009).

Graichen, K., Hagenmeyer, V. and Zeitz, M. "Van de vusse cstr as a benchmark problem for nonlinear feedforward control design techniques", IFAC Proceedings Volumes, 37, 1123-1128.(2004).

Graichen, K., Hagenmeyer, V. and Zeitz, M. "Design of adaptive feedforward control under input constraints for a benchmark cstr based on a bvp solver", Computers \& Chemical Engineering, 33, 473-483.(2009).

Gujer, W.; "Systems analysis for water technology", Berlin, Germany., Springer, (2008).

Klatt, K.-U. and Engell, S. "Rührkesselreaktor mit parallel-und folgereaktion", VDI BERICHTE, 1026, 101-101.(1993).

Klatt, K.-U. and Engell, S. "Gain-scheduling trajectory control of a continuous stirred tank reactor", Computers \& Chemical Engineering, 22, 491502.(1998). 
Kroll, A. and Schulte, H. "Benchmark problems for nonlinear system identification and control using soft computing methods: Need and overview", Applied Soft Computing, 25, 496-513.(2014).

Kvasnica, M., Herceg, M., Čirka, L. and Fikar, M. "Model predictive control of a cstr: A hybrid modeling approach", Chemical papers, 64, 301309.(2010).

Perez, H., Ogunnaike, B., and Devasia, S. (2002). Output tracking between operating points for nonlinear processes: Van de vusse example. pp. 3281 3286 Proceedings of the 2002 American Control Conference (IEEE Cat. No. CH37301), IEEE.

Rothfuss, R., Rudolph, J. and Zeitz, M. "Flatness based control of a nonlinear chemical reactor model", Automatica, 32, 1433-1439.(1996).

Shaqarin, T, and Abdalla. M. "Simultaneous control of liquid level and temperature using feedback linearization techniques", Proceedings of the 20th IASTED International Conference. 670 (814), 71 (2009).

Shaqarin, T., N. Alshabatat, N., and B.R. Noack."Stabilizations of strange attractors by feedback linearization”, Research Journal of Applied Sciences, Engineering and Technology, 8 (1), 43-47. (2014)

Slotine, J.-J.E., and Li, W.; "Applied nonlinear control", Prentice Hall Englewood Cliffs, NJ, (1991).

Van de Vusse, J. "Plug-flow type reactor versus tank reactor", Chemical Engineering Science, 19, 994-996.(1964). 